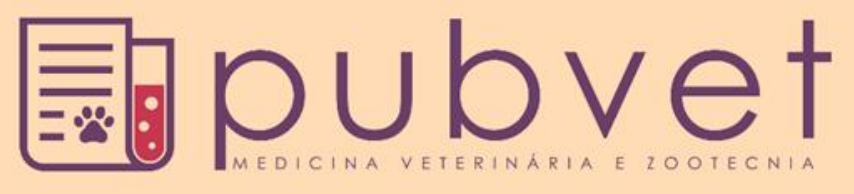

ISSN 1982.1263

https://doi.org/10.31533/pubvet.v13n6a351.1-5

\title{
Linfoma alimentar linfocítico em um felino: terapia com lomustina e prednisona - Relato de caso
}

\author{
Bruna Cenci Ortiz ${ }^{1 *}$, César Augusto Soares $^{1 \bullet}$, Veridiane da Rosa Gomes ${ }^{2} \bullet$, Priscila \\ Secchi $^{2} \odot$, Francisco Jorge Schulz Júnior ${ }^{3 \oplus}$, Maria Inês Witz ${ }^{4} \bullet$, Gisele Barcelos Seberino ${ }^{1 \oplus}$ \\ ${ }^{1}$ Médico(a) Veterinária Residente de Clínica Médica de Pequenos Animais do Hospital Veterinário da Universidade Lutera do Brasil-Canoas/RS-Brasil. \\ 2 Médica Veterinária do Hospital Veterinário da Universidade de Passo Fundo - RS/Brasil. \\ 3 Acadêmico do curso de Medicina Veterinária da Universidade de Passo Fundo - RS/Brasil. \\ 4 Professora Doutora do curso de Medicina Veterinária da Universidade Lutera do Brasil-Canoas/RS-Brasil. \\ *Autor para correspondência, E-mail: bruna.ortizvet@hotmail.com
}

Resumo. Dentre as neoplasias hematopoiéticas mais observadas na espécie felina, cita-se o linfoma. Sendo classificado de acordo com o sítio anatômico afetado, a sua forma alimentar é considerada a segunda neoplasia mais encontrada no trato gastrintestinal de gatos, podendo acometer fígado, baço e pâncreas. Animais idosos e/ou portadores de retroviroses possuem maior risco para o desenvolvimento da doença. A sintomatologia clínica varia conforme a localização, idade do paciente e presença ou não de comorbidades. $\mathrm{O}$ tratamento do linfoma alimentar objetiva melhorar a qualidade e aumentar o tempo de vida dos pacientes. Dessa forma destaca-se a importância do diagnóstico precoce, por meio de exames hematológicos, bioquímicos e de imagem, além da realização de biópsia intestinal. $\mathrm{O}$ acompanhamento de pacientes pertencentes ao grupo de risco também é outro fator essencial para o reconhecimento da doença. Objetiva-se com o presente trabalho relatar o caso de um felino, fêmea, sete anos de idade, com histórico de hiporexia, prostração, êmese e emagrecimento progressivo. Após exames complementares, concluiuse tratar de um quadro de linfoma alimentar linfocítico, optando-se pela quimioterapia com lomustina e prednisona. A terapia demonstrou poucos efeitos colaterais e resposta eficiente no controle da doença.

Palavras-chave: gatos, lomustina, oncologia, pequenos animais, quimioterapia

\section{Lymphocytic alimentary lymphoma in a feline: therapy with lomustine and prednisone - Case report}

Abstract. Among the hematopoietic neoplasms most observed in the feline species, lymphoma is mentioned. Being classified according to the anatomical site affected. The alimentary form is considered the second most common neoplasia found in the gastrointestinal tract of cats, which can affect the liver, spleen and pancreas. Older animals and/or retrovirus carriers have a bigger risk for the development of the disease. Clinical symptomatology varies according to the location, the age of the patient and the presence or absence of comorbidities. The treatment of the lymphocytic alimentary lymphoma aims to improve quality and increase the life span of patients. Thus, the importance of early diagnosis, through hematological, biochemical and imaging tests, as well as intestinal biopsy is highlighted. The follow-up of patients belonging to the risk group is also another essential factor for the recognition of the disease. The objective of this work is to report the case of a seven-year-old female feline with a history of hyporexia, prostration, emesis and progressive weight loss. After further examination, it was diagnosed a lymphocytic alimentary lymphoma and the treatment was with chemotherapy with lomustine and 
prednisone. The therapy demonstrated few side effects and an efficient response to disease control.

Key words: cats, lomustine, oncology, small animals, chemotherapy

\section{Linfoma alimentario linfocítico en un felino: terapia con lomustina y prednisona - Reporte de un caso}

Resumen. Entre las neoplasias hematopoyéticas más observadas en la especie felina, se cita el linfoma. Siendo clasificado de acuerdo con el sitio anatómico afectado. Su forma alimentaria es considerada la segunda neoplasia más encontrada en el tracto gastrointestinal de gatos, pudiendo afectar el hígado, el bazo y el páncreas. Los animales viejos y/o los portadores de retrovirus tienen mayor riesgo para el desarrollo de la enfermedad. La sintomatología clínica varía según la ubicación, la edad del paciente y la presencia o no de comorbilidades. El tratamiento del linfoma alimentario tiene como objetivo mejorar la calidad y aumentar el tiempo de vida de los pacientes. De esta forma se destaca la importancia del diagnóstico precoz, por medio de exámenes hematológicos, bioquímicos y de imagen, además de la realización de biopsia intestinal. El seguimiento de pacientes pertenecientes al grupo de riesgo también es otro factor esencial para el reconocimiento de la enfermedad. Se objetiva con el presente trabajo relatar el caso de un felino, hembra, siete años, con histórico de hiporexia, postración, emesis y adelgazamiento progresivo. Después de exámenes complementarios, se concluyó tratar de un cuadro de linfoma alimentario linfocítico, optando por la quimioterapia con lomustina y prednisona. La terapia demostró pocos efectos colaterales y una respuesta eficaz en el control de la enfermedad.

Palabras claves: gatos, lomustina, oncología, pequeños animales, quimioterapia

\section{Introdução}

Os linfomas, também chamados de linfossarcomas, originam-se principalmente nos órgãos linfóides, mas pode se desenvolver na maioria dos órgãos (Daleck et al., 2008). O linfoma alimentar é uma das formas da doença e afeta o trato gastrointestinal podendo apresentar desde uma infiltração intestinal sem presença de massa palpável, até envolvimento hepático, pancreático, esplênico e de linfonodos mesentéricos (Vail \& Ogilvie, 2003).

A incidência é maior em felinos machos maduros e em animais positivos para retroviroses (Amorim et al., 2006). Os sinais clínicos observados são diversos e variáveis, dependem da localização da neoplasia, do estágio clínico do paciente e da associação com o vírus da imunodeficiência felina (FIV) e com o vírus da leucemia felina (FeLV), que predispõe a uma maior incidência à doença (Chandler et al., 2006). O diagnóstico é desafiador, visto que enfermidades inflamatórias crônicas do trato gastrointestinal podem ocasionar sintomatologia similar (Wilson, 2008). A realização de exames complementares é fundamental para o diagnóstico, hemograma e perfil bioquímico auxiliam na avaliação geral do paciente e a ultrassonografia abdominal tem a capacidade de mostrar infiltrações neoplásicas e alterações na arquitetura dos órgãos, podendo ser opção para realização de aspirados e biópsias, sendo essa a forma final de diagnóstico (Dobson et al., 2006).

O tratamento do linfoma alimentar objetiva melhorar a qualidade e aumentar o tempo de vida dos pacientes (Vail \& Ogilvie, 2003). A quimioterapia é considerada a terapia de eleição, pois a doença frequentemente tem comprometimento sistêmico (Daleck et al., 2016). Nos últimos anos, um novo protocolo quimioterápico tem sido aplicado, a lomustina associada a prednisona. A lomustina possui fácil aplicação e poucos efeitos colaterais, é utilizada atualmente no tratamento de neoplasias cerebrais em humanos e no tratamento de linfoma cutâneo em cães e gatos (Nelson \& Couto, 2015), sendo poucos os relatos sobre seu uso em linfomas alimentares de felinos .

\section{Relato de caso}

Foi atendido um felino, fêmea, de sete anos de idade, sem raça definida, castrada, com 2,1 kg de massa corporal, apresentando hiporexia, prostração, êmese e emagrecimento progressivo. Havia 
histórico anterior de manifestação dos mesmos sinais em outras duas ocasiões, com evidência de espessamento de alças intestinais em ultrassonografias realizadas. Ao exame clínico, observou-se mucosas pálidas e à palpação abdominal espessamento difuso das alças intestinais.

Foram realizados hemograma completo, bioquímica sérica (ureia, creatinina, alanina amino transferase (ALT), gama glutamil transferase e glicose), urinálise, relação proteína/creatinina urinária, ultrassonografia abdominal, teste sorológico rápido para vírus da FIV e da FeLV, radiografia torácica e histopatologia de amostras de intestino delgado (duodeno e jejuno) coletadas por biópsia incisional. Os exames complementares demonstraram discreto aumento de alanina amino transferase e eosinofilia, além de teste sorológico rápido positivo para leucemia viral felina e para imunodeficiência viral felina. Os exames de imagem apresentaram dilatação do ducto cístico e espessamento de parede da vesícula biliar, parênquima hepático grosseiro e hiperecogênico e alças intestinais espessadas com até $0,4 \mathrm{~cm}$ e peristaltismo aumentado.

Devido ao estado clínico do paciente e com base nos resultados dos exames procedeu-se com a internação. A terapia instituída consistiu em citrato de maropitant $(1 \mathrm{mg} / \mathrm{kg}, \mathrm{SC}, \mathrm{SID}$, três dias), ampicilina sódica (20 mg/kg, IV, TID, dez dias), metronidazol (15 mg/kg, IV, cinco dias), cianocobalamina (1000 mg/gato, IM, semanal por seis semanas), ácido ursodesoxicólico $(15 \mathrm{mg} / \mathrm{kg}$, VO, SID, 30 dias), silimarina (20 mg/kg, VO, SID, 30 dias), ranitidina (1 mg/kg, SC, BID, sete dias), mirtazaprina $(3,75 \mathrm{mg} / \mathrm{gato}, \mathrm{VO}$, uma única dose) e fluidoterapia com ringer lactato de sódio.

No quinto dia de internação, a paciente demonstrou melhora do quadro sendo submetido a biópsia incisional do duodeno e jejuno. O exame histopatológico dos fragmentos demonstrou neoplasia linfóide de pequenas células ulcerando mucosa e invadindo submucosa (Figura 1), caracterizada por severo infiltrado linfoide com núcleos pequenos, hipercorados, com formações nodulares e densos lençóis, caracterizando linfoma intestinal linfocítico. Não foi possível realizar biópsia hepática e de segmento do íleo.

Após uma semana da biópsia foi instituído o protocolo quimioterápico domiciliar com lomustina 10 $\mathrm{mg} /$ gato, VO, a cada quatro semanas e prednisona $4 \mathrm{mg} / \mathrm{kg}$, VO, SID, durante uma semana, após $2 \mathrm{mg} / \mathrm{kg}$, SID, VO por mais duas semanas e após a mesma dose a cada 48 horas até final do protocolo (seis ciclos) e retirada gradual.

Na primeira semana de tratamento, a paciente apresentou hiporexia, sinal clínico que normalizou já na segunda semana. Após a terceira semana, foi observado ganho de peso evidente e a ultrassonografia demonstrou valores normais na aferição da espessura da parede intestinal $(0,27 \mathrm{~cm})$.

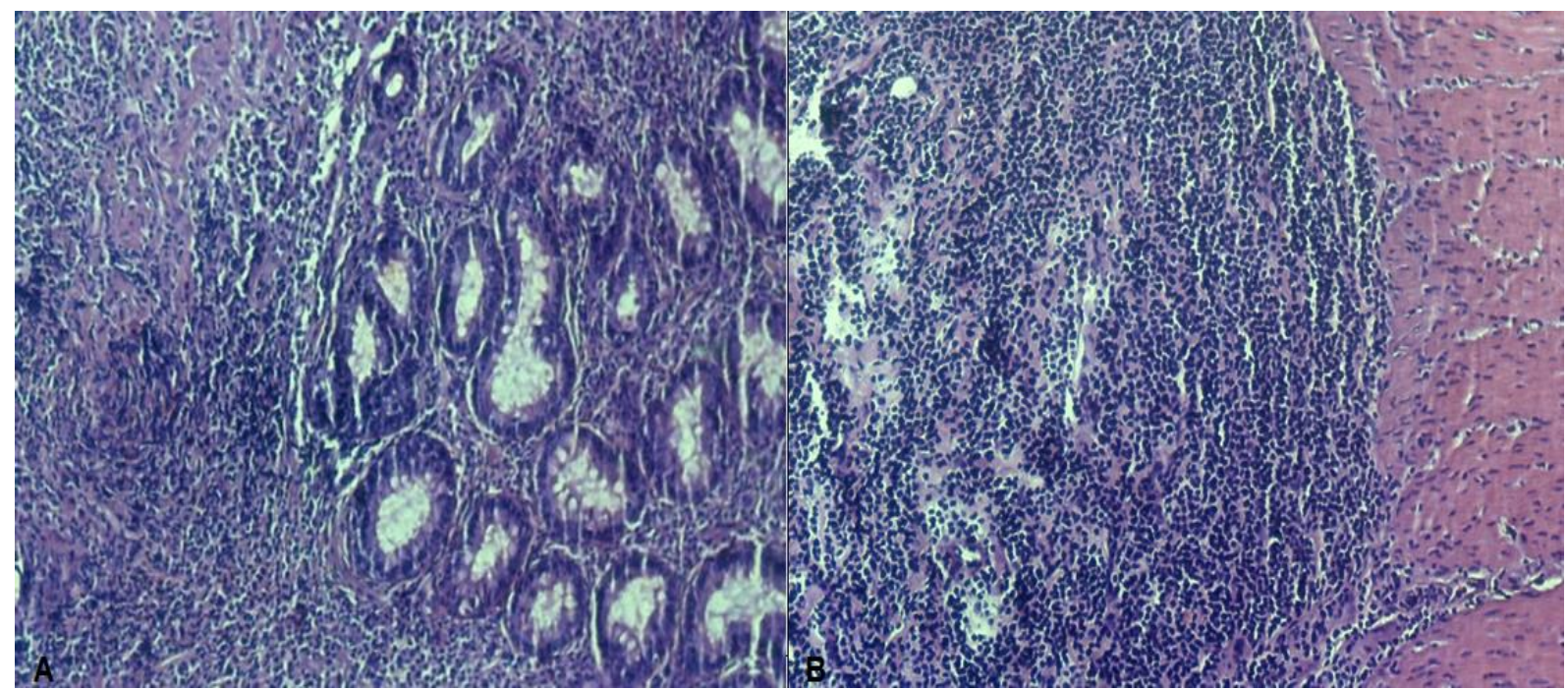

Figura 1. Imagem histopatológica de intestino delgado de um felino, fêmea, SRD, de 7 anos de idade. (A) Infiltrado linfoide difuso severo de células pequenas neoplásicas com invasão da mucosa e pedra da arquitetura do órgão. (B) Infiltrado neoplásico linfóide difuso severo de pequenas células na submucosa do intestino delgado com perda de arquitetura do orgão, observando-se invasão das células neoplásicas na camada muscular e destruição da mucosa com formação de úlcera. 


\section{Discussão}

O linfoma, não somente a forma alimentar, é uma neoplasia bastante comum na espécie felina. O paciente tratava-se de um felino, de sete anos de idade, corroborando com o observado por Vail et al. (2001), no que diz respeito a idade do animal, embora o sexo não seja o mais acometido. Animais positivos para retroviroses possuem um risco maior de desenvolver linfoma (Daleck et al., 2016), sendo a paciente soro positivo tanto para FeLV quanto FIV, isso a tornou ainda mais suscetível ao desenvolvimento da doença. Os sinais clínicos manifestados eram bastante inespecíficos, portanto, a realização de exames complementares foi importante para descarte de doenças que causem alterações similares, como outras doenças intestinais (Wilson, 2008).

As alterações em exames hematológicos e bioquímicos dependem muito do estágio da doença, presença de massas ou não e gravidade dos sinais clínicos manifestados. A eosinofilia apresentada é descrita por Norsworthy et al. (2004) podendo ser explicada pela inflamação crônica da parede intestinal. As elevações nos parâmetros hepáticos, como de ALT, podem estar relacionados a infiltração neoplásica do parênquima hepático, característica do estádio IV (Daleck et al., 2016) ou jejum prolongado em que se encontrava a paciente.

A realização de ecografia abdominal evidenciou o espessamento de alças intestinais, o qual também foi possível notar à palpação abdominal. Em alguns casos pode atingir fígado, alteração observada na ecografia (Wilson, 2008). Entretanto, a paciente encontrava-se sem alterações no baço e estômago, conforme sugerido pelo mesmo autor. Segundo Matiz (2016) o diagnóstico do linfoma alimentar costuma ser feito em média seis meses após o início da manifestação dos sinais clínicos. O que foi observado no caso, já que a paciente tinha histórico de manifestações clínicas anteriores. A realização de radiografia torácica é indicada em pacientes confirmados ou com suspeita de linfoma, para investigar possíveis massas e linfadenopatia. Entretanto, são raras no linfoma linfocítico (Daleck et al., 2016; Norsworthy et al., 2004). No presente relato não foram observadas alterações nesse exame.

A administração de cobalamina foi indicada, devido à suspeita de linfoma. Sabe-se que no linfoma intestinal sua absorção e de outros nutrientes é severamente alterada, além de acarretar sinais clínicos indesejáveis e causar uma resposta inadequada aos fármacos quimioterápicos (Wilson, 2008). A estabilização do paciente foi importante tanto para realização da biópsia, quanto para o protocolo quimioterápico. A quimioterapia foi a opção de escolha, que está de acordo com Daleck et al. (2016).

A realização de biópsia incisional pela laparotomia é indicada por Wilson (2008), sendo a forma de diagnóstico definitiva, embora sendo indicado, não foi possível coletar amostras hepáticas e do íleo. $\mathrm{O}$ resultado histopatológico evidenciou linfoma de células pequenas, com infiltração de mucosa e invadindo submucosa, achado descrito por Norsworthy et al. (2004).

A classificação de estádio da doença de acordo com a (Organização Mundial de Saúde) OMS, concorda com os dados descritos por Daleck et al. (2016), onde a maioria dos gatos diagnosticados estão entre os estádios III e IV, devido aos sinais inespecíficos apresentados, que permite desenvolvimento da doença com diagnóstico tardio.

A quimioterapia com protocolos COP (ciclofosfamida, vincristina e prednisona) ou CHOP (Lasparaginase, ciclofosfamida, doxorrubicina, vincristina e prednisona) embora sendo os mais utilizados no tratamento do linfoma, tendem a provocar efeitos colaterais mais severos em felinos (Wilson, 2008). Dessa forma, optou-se pelo tratamento, ainda em estudo, com o uso da lomustina em combinação com a prednisona, por tratar-se de um protocolo de fácil administração, baixo custo, relatos de boa resposta terapêutica e baixíssimos índices de efeitos colaterais (Nelson \& Couto, 2015). A paciente apresentou como único efeito colateral ao início da terapia hiporexia, que perdurou durante a primeira semana de tratamento, com consequente normalização do apetite e até mesmo ganho de peso passadas três semanas do início da terapia.

Para monitoração da evolução da doença foi utilizada a ultrassonografia abdominal, que em até 90\% dos gatos com doença de manifestação crônica, demonstra anormalidades, sendo as mais comuns o espessamento da parede do intestino delgado, podendo haver infiltração visível em fígado (Wilson, 2008), como observado ao primeiro exame realizado. Após três semanas do início da terapia, a 
ultrassonografia demonstrou redução significativa do espessamento da mucosa intestinal de até $0,4 \mathrm{~cm}$ inicialmente, para espessura normal de $0,27 \mathrm{~cm}$.

O prognóstico para gatos soropositivos é desfavorável, porém a resposta à quimioterapia não é diferente à dos gatos negativos, motivo pelo qual foi indicado o tratamento (Dobson et al., 2006). A sobrevida de gatos positivos para retroviroses, mesmo seguindo alguma terapia quimioterápica é de três a quatro meses (Amorim et al., 2006). Porém, desde o diagnóstico até o momento a paciente encontrase com tempo médio de sobrevida de sete meses.

\section{Conclusão}

O tratamento do linfoma ainda é um desafio, pois acaba muitas vezes gerando efeitos colaterais significativos, além de curto tempo de vida e da remissão da neoplasia, principalmente no que diz respeito aos gatos soropositivos para retroviroses, que acabam por ter um tempo de sobrevida ainda menor. Devido a esses fatores, a tratamentos quimioterápicos dispendiosos e a disponibilidade de tempo e dedicação dos proprietários, a maioria prefere não realizar a terapia e muitas vezes optam pela eutanásia. A lomustina demonstrou-se uma alternativa no caso relatado devido ao custo acessível e fácil administração, apresentando também poucos efeitos colaterais e resposta terapêutica satisfatória. Mesmo tratando-se de um felino portador de retroviroses, o resultado da terapia foi semelhante a outros casos de linfoma alimentar em gatos soronegativos em tratamento com a droga.

\section{Referências bibliográficas}

Amorim, F. V., Souza, H. J. M. \& Ferreira, A. M. R. (2006). Linfoma mediastinal em gatos - relato de caso. Clínica Veterinária, 6368-74.

Chandler, E. A., Gaskell, C. J. \& Gaskell, R. M. (2006). Clínica e terapêutica em felinos. São Paulo: Editora Roca.

Daleck, C. R., De Nardi, A. B., Rodigheri, S. M. \& Motta, F. R. (2008). Neoplasia do sistema urinário (Vol. 1). São Paulo: Roca.

Daleck, C. R., Fonseca, C. S. \& Canola, J. C. (2016). Oncologia em cães e gatos. Rio de Janeiro: Roca.

Dobson, J., Villiers, E. \& Morris, J. (2006). Diagnosis and management of leukaemia in dogs and cats. In practice, 28(1):22-31.

Matiz, O. R. S. (2016). Linfoma alimentar. In G. A. Mazzotti \& M. R. Roza (Eds.), Medicina felina essencial: guia prático. Curitiba, Paraná, Brasil: Equalis.

Nelson, R. W. \& Couto, C. G. (2015). Medicina interna de pequenos animais. Amsterdan: Elsevier Editora.

Norsworthy, G. D., Crystal, M. A., Grace, S. F. \& Tilley, L. P. (2004). O paciente felino. São Paulo: Roca, 3300.

Vail, D. M., Macewen's \& Young, K. M. (2001). Canine lymphoma and lymphoid leukemias. In S. J. Witrow \& E. G. Macewen's (Eds.), Small animal clinical oncology. $3^{\circ} \mathrm{rd} / \mathrm{ed}$. Philadelphia: Saunders Company:558-590. (pp. 558-590). Philadelphia, USA: Saunders Company.

Vail, D. M. E. \& Ogilvie, G. K. (2003). Neoplasias linfoides. In S. J. Bichard \& R. G. Sherding (Eds.), Manual Saunders: Clínica de Pequenos Animais (pp. 227-233). São Paulo, Brasil: Roca.

Wilson, H. M. (2008). Feline alimentary lymphoma: Demystifying the enigma. Topics in Companion Animal Medicine, 23177-184.

Recebido: 6 de maio, 2019.

Aprovado: 1 de junho, 2019.

Publicado: 27 de junho, 2019.

Licenciamento: Este artigo é publicado na modalidade Acesso Aberto sob a licença Creative Commons Atribuição 4.0 (CC-BY 4.0), a qual permite uso irrestrito, distribuição, reprodução em qualquer meio, desde que o autor e a fonte sejam devidamente creditados. 